\title{
Antennal asymmetry is not associated with social behaviour in Australian Hymenoptera
}

\author{
Christopher B. Freelance $^{1, *}$, Megha Majoe ${ }^{1}$, Simon M. Tierney $^{2,1}$ \& Mark A. Elgar ${ }^{1}$ \\ ${ }^{1}$ School of BioSciences, The University of Melbourne, Victoria 3010, Australia
}

${ }^{2}$ Hawkesbury Institute for the Environment, Western Sydney University, Penrith, NSW 2751, Australia

*christopher.freelance@unimelb.edu.au

\section{Running Title}

Antennal sensilla asymmetry in Australian Hymenoptera

\begin{abstract}
Lateralisation of biological form and function are well known for vertebrates and are being increasingly documented among invertebrates in recent years. Behavioural lateralisation in insects, together with asymmetrical distributions of antennal sensilla, has been linked to the communication challenges faced by social, but not solitary, insects. Recent evidence on patterns of asymmetry in insects outside of the Hymenoptera suggests that this explanation for antennal sensilla asymmetry may not be phylogenetically constrained. We explore this possibility by examining the distribution of antennal sensilla in three species of ants (Formicidae), the meat ant Iridomyrmex purpureus (Dolichoderinae), the green tree ant Oecophylla smaragdina (Formicinae) and the shield ant Meranoplus sp. (Myrmicinae) in which colony organisation is eusocial, and two species of nomiine bees, Mellitidia tomentifera and Reepenia bituberculata (Halictidae: Nomiinae) where colony organisation is not eusocial. Our results demonstrate that while there are differences in the left-right asymmetry of antennal sensilla basiconica in workers of the formicine ant I. purpureus, there is no consistent sensilla asymmetry across the five species. We find a negative correlation between antennal sensilla density and body size in $R$. bituberculata, which was not apparent

This is the author manuscript accepted for publication and has undergone full peer review but has not been through the copyediting, typesetting, pagination and proofreading process, which may lead to differences between this version and the Version of Record. Please cite this article as doi: 10.1111/aen.12368
\end{abstract}

This article is protected by copyright. All rights reserved. 
in the other species. Our results contradict the suggestion that asymmetrical distribution of antennal sensilla is associated with the evolution of eusocial behaviour.

Keywords sensilla, asymmetry, insect, ant, bee, social behaviour

\section{INTRODUCTION}

The ability to detect cues and signals is essential for all animals, as they provide crucial information about the location of resources, enemies and reproductive partners, and for more social species the identity of individuals. Efficient sensory organs are key to this process, and insects have evolved considerable structural diversity in their sensory organs that allow them to detect and acquire this information. The primary means for detecting movement, temperature, humidity and informative odours among insects are via sensory receptors (sensilla) on their antennae, which occur in a variety of forms (Chapman 1982; Norton \& Vinson 1974).

Frasnelli et al. (2010a) speculate that specialisation of antennal function may be associated with the asymmetrical distribution of sensilla density between the left and right antenna in the honeybee Apis mellifera (Apidae). Furthermore, these bees have lateralisation of olfactory function (Rigosi et al. 2011; Rogers \& Vallortigara 2008), learning (Anfora et al. 2010; Letzkus et al. 2006) and memory (Frasnelli et al. 2010b; Rogers \& Vallortigara 2008). Behavioural trials demonstrate that A. mellifera prefer to use the right antenna when responding to olfactory cues, corresponding with a higher predominance of one type of olfactory sensilla (Letzkus et al. 2006). A similar corresponding behavioural lateralisation and accompanying sensilla asymmetry is found in the bumblebee Bombus terrestris (Apidae) (Anfora et al. 2011). Several lines of evidence suggest that this asymmetry is related to eusocial colony organisation (Anfora et al. 2011; Frasnelli et al. 2012): workers of $A$. mellifera preferentially use their right antennae in social interactions (Rogers et al. 2013); similar olfactory learning asymmetry is absent in the solitary bee Osmia cornuta (Megachilidae) (Anfora et al. 2010); and there is no antennal sensilla asymmetry in the solitary bee Osmia rufa (Megachilidae) (Frasnelli \& Vallortigara 2017). These findings collectively provide evidence for a population-level asymmetry whereby the right antenna 
presents on average a higher density of some olfactory sensilla and thus is preferentially used in social and odour-learning amongst only these social bee species (Frasnelli \& Vallortigara 2017). Such population-level lateralisation has been suggested as a potential evolutionary stable strategy for social species, whereby the asymmetry possessed by each individual in a population to enhance the individual's behavioural and neural efficiency (Levy 1977; Rogers et al. 2004) is aligned to facilitate efficient interactions between these conspecifics (Ghirlanda \& Vallortigara 2004).

Some non-social bee species demonstrate behavioural lateralisation in olfactory recall but lack the antennal sensilla asymmetry that accompanies this behavioural phenomenon in A. mellifera (Frasnelli \& Vallortigara 2017), which suggests that sensilla asymmetry alone may not explain the behavioural lateralisation observed at the population level. The role of eusociality in driving these sensilla asymmetries in the same way it appears to drive behavioural lateralisation is contradicted by discoveries of asymmetrical antennal sensilla density in the non-social parasitoid wasp Anastatus japonicus (Eupelmidae) (Meng et al. 2012); an absence of any expected side-biased sensilla density in the social stingless bee Austroplebeia australis (Apidae) (Frasnelli \& Vallortigara 2017); and asymmetrical antennal grooming behaviour - notionally linked to sensilla asymmetry - in the asocial cockroach Periplaneta americana (Blattodea: Blattidae) (Zhukovskaya \& Lychakov 2016).

While the exploration of behavioural lateralisation biases spans many insect clades (Frasnelli et al. 2012), empirical investigations of the link between antennal sensilla asymmetry and social behaviour independent of behavioural lateralisation within the Hymenopteran insects is restricted to social bees. If antennal sensilla asymmetry is indeed related to complex social organisation (eusociality), we would expect clear asymmetrical densities of antennal sensilla in non-bee eusocial insects, but not in the non-social bees/Hymenoptera. Here we explore aspects of asymmetry outside the social bees by comparing sensilla distribution in three species of ant (the Australian meat ant Iridomyrmex purpureus, the Australian green tree ant Oecophylla smaragdina and an unidentified/undescribed shield ant Meranoplus sp.) - all of which are eusocial - with two species of social Australian nomiine bees (Mellitidia tomentifera and Reepenia bituberculata) 
that are not considered eusocial. In line with the above predictions, we would expect clear asymmetrical antennal sensilla distributions in the ants but not in the two species of nomiine bees.

\section{MATERIALS AND METHODS}

\section{Study species}

The meat ant $I$. purpureus is widespread throughout Australia, and ecologically dominant with characteristic mound-shaped nests and strong colony defence behaviours (Thomas et al. 1999). While largely undescribed at the species level, shield ants (Meranoplus) are predominantly subterranean and nest in soil, distributed through both northern and southern Australia, especially in arid and semi-arid regions (Andersen 2006). The workers analysed in the present study are believed to be Meranoplus curvispina (Schödl 2004), but this identification has not been confirmed and so are referred to as Meranoplus sp. The Old World green tree ant Oecophylla smaragdina is an ecologically dominant arboreal species distributed in northern Australia (Hölldobler 1983; Lokkers 1986). The leaves comprising the characteristic leaf nests are bound using larval silk, and the trees supporting these nests are defended by highly aggressive workers (Gill et al. 2013; Hölldobler 1983; Lokkers 1986). This species also has two castes of worker ant (major and minor) as well as the obligatory queen caste (Babu et al. 2011).

Bees from the halictid subfamily Nomiinae are typically ground nesting. Although the nesting biology for the two species in our study have not been described, there are currently no known eusocial species of Nomiinae, and roughly half of the nomiine species studied to date are thought to be social (reviewed by Michener 1969; Michener 2007; Wcislo and Engel 1996), with casteless social organisation in some lineages (as defined by Dew et al. (2016)), and only two species showing potential for semisocial organisation (Batra 1966).

\section{Data collection and analysis}


Workers of I. purpureus and Meranoplus sp. were captured from outside nests at Serendip Sanctuary in Lara, Victoria, Australia in March-April 2016 and placed in 90\% ethanol for preservation and transport. A small nest of O. smaragdina was collected from near James Cook University in Townsville, Queensland, Australia in May 2017. All ants of a given species were from the same colony. Ants were sacrificed by exposure to acetone in a killing jar and major workers glued to pinned triangles of cardboard. Pinned specimens of $M$. tomentifera and $R$. bituberculata were obtained from the Museum Victoria entomology collection, which were originally field-collected from sites in Queensland, Australia.

Pinned specimens were mounted onto a piece of foamcore board covered with black cardboard, and the foamcore block mounted on an electron microscopy stub. Specimens were imaged with low-vacuum un-coated scanning electron microscopy (SEM) on a FEI Quanta 200F scanning electron microscope at the Bio21 Advanced Microscopy Facility (Bio21 Institute, The University of Melbourne, Parkville, Victoria, Australia). For all specimens, a spot size of 2.0 and pressure of 0.50 mbar was used, with high a voltage of $7.5 \mathrm{kV}$ for the bee specimens and $10 \mathrm{kV}$ for the ant specimens. The dorsal surface of the apical antennomere (segment) of each antenna was imaged at the sufficient magnification (>1200x in all cases) to allow identification of different types of antennal sensilla for that particular specimen. The head of each specimen was also imaged.

Using FIJI (Schindelin et al. 2012), the number of sensilla on the dorsal surface of the apical antennomere was counted and the area of that antennomere measured $\left(\mu \mathrm{m}^{2}\right)$ to calculate the sensilla density (no. of sensilla per $\mu \mathrm{m}^{2}$ ) of that antennomere. For the ant specimens ( $\mathrm{N}=5$ workers of each species), sensilla were typed following Dumpert (1972). For the bee specimens $(\mathrm{N}=6$ workers of $M$. tomentifera and $\mathrm{N}=5$ workers of $R$. bituberculata), sensilla were typed following Carvalho et al. (2017) and Frasnelli et al. (2010a). Head width just posterior to the eyes was calculated as a measure of body size (Boudinot \& Fisher 2013; Spaethe et al. 2007; Wild 2007).

For each species, the variation in the density of each type of antennal sensilla was examined with a general linear model with side (left, right) and head width as fixed factors 
with variance partitioned using ordinary least squares. Some measures were natural log transformed to improve the distribution. Statistical analysis was performed using JMP 13.0.0 for Windows (SAS Institute, Cary, NC, USA).

\section{RESULTS}

Ants

Four types of sensilla were identified: sensilla trichodea curvata, sensilla basiconica, sensilla chaetica and sensilla trichoid-II (Figure 1A).

For I. purpureus, there was no difference in the mean density of sensilla between the left and right antennae for sensilla trichoid-II or chaetica or in the mean natural log density of sensilla trichodea curvata (Table 1). However, the left antenna had a significantly higher density of sensilla basiconica than did the right antenna (Table 1). There was no significant correlation between head width and the density of sensilla trichoid-II $\left(F_{1,7}=2.699, p=\right.$ $0.144)$, sensilla chaetica $\left(F_{1,7}=2.388, p=0.166\right)$, sensilla basiconica $\left(F_{1,7}=2.473, p=0.160\right)$ or the natural $\log$ of the density of sensilla trichodea curvata $\left(F_{1,7}=1.598, p=0.247\right)$.

For Meranoplus sp., there was no difference in the mean density of sensilla between the left and right antennae for sensilla trichoid-II, chaetica or sensilla basiconica or in the mean natural log density of sensilla trichodea curvata (Table 1). There was no significant correlation between head width and the density of sensilla trichoid-II ( $F_{1,6}=0.0031, p=$ $0.957)$, sensilla chaetica $\left(F_{1,6}=0.423, p=0.540\right)$, sensilla basiconica $\left(F_{1,6}=0.5063, p=\right.$ $0.504)$ or the natural $\log$ of the density of sensilla trichodea curvata $\left(F_{1,6}=0.0033, p=\right.$ $0.956)$.

For O. smaragdina, there was no difference in the mean natural log density of sensilla between the left and right antennae for sensilla trichoid-II, chaetica, basiconica or trichodea curvata (Table 1). There was no significant relationship between head width and the natural $\log$ densities of sensilla trichoid-II $\left(F_{1,8}=1.194, p=0.306\right)$, sensilla chaetica $\left(F_{1,8}=1.091, p\right.$ $=0.327)$, sensilla basiconica $\left(F_{1,8}=2.283, p=0.169\right)$ or sensilla trichodea curvata $\left(F_{1,8}=\right.$ $1.384, p=0.273)$. 


\section{Bees}

Five types of sensilla were identified: sensilla trichodea A, sensilla trichodea B, sensilla basiconica, sensilla chaetica and sensilla placeodea (Figure 1B).

For M. tomentifera, there was no difference in the mean density of sensilla between the left and right antennae for sensilla trichodea A or sensilla trichodea B or in the mean natural log of density of sensilla basiconica, sensilla chaetica or sensilla placodea (Table 1). There was no significant relationship between head width and the densities of sensilla trichodea A $\left(F_{1,9}=0.459, p=0.515\right)$ or sensilla tricohdea B $\left(F_{1,9}=0.0178, p=0.897\right)$, or the natural $\log$ densities of sensilla basiconica $\left(F_{1,9}=1.246, p=0.293\right)$, sensilla chaetica $\left(F_{1,9}=\right.$ $0.877, p=0.373)$ or sensilla placodea $\left(F_{1,9}=1.292, p=0.285\right)$.

For $R$. bituberculata, there was no difference in the mean density of sensilla between the left and right antennae for sensilla trichodea A or sensilla trichodea B or in the mean natural log of density of sensilla basiconica, sensilla chaetica or sensilla placodea (Table 1). There was a significant negative correlation between head width and the densities of sensilla trichodea $\mathrm{A}\left(F_{1,7}=9.561, p=0.0175\right)$ and sensilla tricohdea $\mathrm{B}\left(F_{1,7}=7.911, p=0.026\right)$, and the natural $\log$ densities of sensilla basiconica $\left(F_{1,7}=10.02, p=0.0158\right)$, sensilla chaetica $\left(F_{1,7}=21.34, p=0.0024\right)$ and sensilla placodea $\left(F_{1,7}=12.92, p=0.0088\right)$.

\section{DISCUSSION}

We found no evidence of asymmetry in the density of antennal sensilla in three species of ants and two species of non-eusocial bee. The density of sensilla basiconica on the left antennae of workers the meat ant I. purpureus was statistically significantly higher $(\mathrm{p}=0.05)$ than that of the right antennae. While this result would be consistent with a population-level asymmetry in sensilla basiconica density for I. purpureus, given the number of statistical tests performed this marginally significant result requires further investigation. Sensilla density did correlate negatively with body size in the nomiine bee $R$. bituberculata. The lack of antennal asymmetry in sensilla density in the non-eusocial bees $M$. tomentifera and $R$. bituberculata are consistent with previous studies (Frasnelli \& Vallortigara 2017). 
It is of note that sample size may also have contributed to the absence of results fully consistent with our hypotheses. While larger sample sizes would be desirable, both $M$. tomentifera and R. bituberculata, and to a lesser extent many species of Meranoplus shield ants, have low prevalence at the population level and museum specimens are therefore relatively scarce. This rarity makes the inclusion of such species in these analyses valuable despite the reduction in statistical power associated with our choice of study species.

The lack of consistent antennal asymmetry in sensilla density across the ant species studied contrasts with previous reports on sensilla asymmetries in other eusocial insects (Anfora et al. 2011; Frasnelli et al. 2010a) that sparked speculation that sociality may be the driver of said asymmetry. Our results add to other contrasting evidence: namely, no such asymmetry in a eusocial stingless bee (Frasnelli \& Vallortigara 2017) and the finding of asymmetrical antennal sensilla distribution in a non-social parasitoid wasp (Meng et al. 2012), which raises the possibility that the asymmetry may have functions not associated with social behaviour. While demonstrations of behavioural lateralisation in the species studied are lacking, that the behavioural lateralisation and antennal sensilla distribution asymmetries tend to occur adjunctly in this paradigm (e.g. Anfora et al. 2011; Letzkus et al. 2006) suggests that either morphological or behavioural bias may be a productive avenue of exploration to elucidate the driver(s) of this intriguing population-level asymmetry. This is especially poignant given that not all species known to possess a behavioural lateralisation possess an asymmetry in antennal sensilla distribution (Frasnelli \& Vallortigara 2017), suggesting that both morphological and behavioural biases warrant investigation in their own rights.

Methodological differences may account for some of the discrepancies between our results and those of previous studies. The asymmetry in some studies was explored for most types of sensilla (Frasnelli et al. 2010a), whereas our study did not assess peg- or pore-like sensilla (e.g. coeloconic and ampullaceous sensilla) which often possess an olfactory, thermoor hygro-receptive function depending on type (Ågren \& Hallberg 1996; Nowińska \& Brożek 2017; Wang et al. 2016). It is possible that the ant species in the present study possess a sidebased asymmetry in the density of these sensilla rather than in the density of hair-like 
sensilla. Importantly, ants do not possess the same range of sensilla found on bees: for example, ants lack the sensilla placodea, which have an olfactory function (McIndoo 1914), that were found to be in higher density on the right than the left antenna of A. mellifera (Frasnelli et al. 2010a; Letzkus et al. 2006). Nevertheless, a similar asymmetry in sensilla placodea has been noted in the non-social parasitoid wasp A. japonicus (Meng et al. 2012), which is consistent with the assertion that eusociality may not be the only factor favouring such asymmetries across the Hymenoptera. Such notions are further reinforced by recent findings in the red mason bee Osmia bicornis (Megachilidae) that asymmetrical antenna use during agonistic social interactions depends more upon the nature of the interaction than upon sociality (Rogers et al. 2016). Combined, these findings suggest that further investigation into the prevalence of antenno-morphological and behavioural asymmetries in social and non-social Hymenoptera, ideally utilising comparative phylogenetic analyses to account for shared phylogeny within the Hymenoptera, is required to elucidate the driver(s) of such asymmetries.

The negative relationship between antennal sensilla density and body size in the bee $R$. bituberculata is not consistent with records of allometric scaling of sensilla density with body size and/or antenna length in bees. For example, larger workers of the bumblebee $B$. terrestris, have both longer antennae and a higher density of some types of antennal sensilla (Spaethe et al. 2007). These workers also have a higher density of sensilla trichodea-A in their right than left antenna (Anfora et al. 2011). The density of sensilla trichodea-A is negatively correlated with body size in $R$. bituberculata. Workers of $R$. bituberculata forage in dim-light (S.M. Tierney pers. obs.), and some species of dim-light active Hymenoptera have both larger compound eye facet size and more ommatidia for their body size compared with their day-active counterparts (Greiner et al. 2007; reviewed by Tierney et al. 2017; Warrant 2017; Wcislo \& Tierney 2009). While trade-off theory predicts that increased investment in one life-history trait is likely to come at the expense of decreased investment in another trait (Stearns 1989; Zera \& Harshman 2001), there is no a-priori reason to expect a trade-off between any particular pair of traits. Nevertheless, a change in photic environment might generate a trade-off in the investment in receptor organs between different sensory 
modalities. Thus, dim-light active species may compensate the greater investment in photoreceptive organs with a lower investment in another sensory-related trait, such as antennae. The negative relationship between sensilla density and body size in $R$. bituberculata may reflect such a trade-off in receptor organ investment between sensory modalities. Inter-specific comparative analyses are required to evaluate this possibility, but interestingly, $M$. tomentifera, which is a close relative of $R$. bituberculata, forages diurnally and sensilla density is not correlated with body size.

\section{ACKNOWLEDGEMENTS}

The authors extend thanks to Roger Curtain at the Bio21 Advanced Microscopy Facility for technical assistance with the scanning electron microscopy, to Parks Victoria for facilitating fieldwork at Serendip Sanctuary, to Qike Wang for collecting the green tree ant specimens and to Ken Walker from Museum Victoria for providing bee specimens from the MV entomology collection. All scanning electron microscopy was performed at the Bio21 Advanced Microscopy Facility. CF is supported by the Australian Government Research Training Program.

\section{REFERENCES}

Ågren, L \& Hallberg, E. 1996 Flagellar sensilla of bumble bee males (Hymenopera, Apidae, Bombus). Apidologie 27, 433-444.

Andersen, AN. 2006 A systematic overview of Australian species of the myrmicine ant genus Meranoplus F. SMITH, 1853 (Hymenoptera: Formicidae). Myrmecologische Nachrichten 8, 157-170.

Anfora, G, Frasnelli, E, Maccagnani, B, Rogers, LJ \& Vallortigara, G. 2010 Behavioural and electrophysiological lateralization in a social (Apis mellifera) but not in a non-social (Osmia cornuta) species of bee. Behavioural Brain Res 206, 236-239.

Anfora, G, Rigosi, E, Frasnelli, E, Ruga, V, Trona, F \& Vallortigara, G. 2011 Lateralization in the Invertebrate Brain: Left-Right Asymmetry of Olfaction in Bumble Bee, Bombus terrestris. PLOS ONE 6, e18903. 
Babu, MJ, Ankolekar, SM \& Rajashekhar, KP. 2011 Castes of the weaver ant Oecophylla smaragdina (Fabricius) differ in the organization of sensilla on their antennae and mouthparts. Current Science 101, 755-764.

Batra, SWT. 1966 Social behavior and nests of some nomiine bees in India (Hymenoptera, Halictidæ). Insectes Sociaux 13, 145-153.

Boudinot, BE \& Fisher, BL. 2013 A taxonomic revision of the Meranoplus F. Smith of Madagascar (Hymenoptera: Formicidae: Myrmicinae) with keys to species and diagnosis of the males. Zootaxa 3635, 301-339.

Carvalho, WJd, Fujimura, PT, Bonetti, AM, et al. 2017 Characterization of antennal sensilla, larvae morphology and olfactory genes of Melipona scutellaris stingless bee. PLOS ONE 12, $\mathrm{e} 0174857$.

Chapman, RF. 1982 Chemoreception: The Significance of Receptor Numbers. Advances in Insect Physiology 16, 247-356.

Dew, RM, Tierney, SM \& Schwarz, MP. 2016 Social evolution and casteless societies: needs for new terminology and a new evolutionary focus. Insectes Sociaux 63, 5-14.

Dumpert, K. 1972 Bau und verteilung der sensillen auf der antennengeißel von Lasius fuliginosus (Latr.) (Hymenoptera, Formicidae). Zeitschrift für Morphologie der Tiere 73, 95116.

Frasnelli, E, Anfora, G, Trona, F, Tessarolo, F \& Vallortigara, G. 2010a Research report: Morpho-functional asymmetry of the olfactory receptors of the honeybee (Apis mellifera). Behav Brain Res 209, 221-225.

Frasnelli, E \& Vallortigara, G. 2017 Distribution of Antennal Olfactory and Non-Olfactory Sensilla in Different Species of Bees. Symmetry 9, 135.

Frasnelli, E, Vallortigara, G \& Rogers, LJ. 2010b Research report: Response competition associated with right-left antennal asymmetries of new and old olfactory memory traces in honeybees. Behav Brain Res 209, 36-41.

Frasnelli, E, Vallortigara, G \& Rogers, LJ. 2012 Left-right asymmetries of behaviour and nervous system in invertebrates. Neuroscience \& Biobehavioral Reviews 36, 1273-1291. 
Ghirlanda, S \& Vallortigara, G. 2004 The evolution of brain lateralization: a game-theoretical analysis of population structure. Proceedings of the Royal Society of London. Series B:

Biological Sciences 271, 853-857.

Gill, KP, Wilgenburg, Ev, Macmillan, DL \& Elgar, MA. 2013 Density of Antennal Sensilla Influences Efficacy of Communication in a Social Insect. The American Naturalist 182, 834840.

Greiner, B, Narendra, A, Reid, SF, Dacke, M, Ribi, WA \& Zeil, J. 2007 Eye structure correlates with distinct foraging-bout timing in primitive ants. Current Biology 17, R879R880.

Hölldobler, B. 1983 Territorial behavior in the green tree ant (Oecophylla smaragdina).

Biotropica 15, 241-250.

Letzkus, P, Ribi, WA, Wood, JT, Zhu, H, Zhang, S-W \& Srinivasan, MV. 2006

Lateralization of Olfaction in the Honeybee Apis mellifera. Current Biology, 1471.

Levy, J. 1977 The Mammalian Brain and the Adaptive Advantage of Cerebral Asymmetry. Annals of the New York Academy of Sciences 299, 264-272.

Lokkers, C. 1986 The distribution of the weaver ant, Oecophylla smaragdina (Fabricius) (Hymenoptera: Formicidae) in Northern Australia. Australian Journal of Zoology 34, 683687.

McIndoo, NE. 1914 The olfactory sense of the honey bee. Journal of Experimental Zoology 16, 265-346.

Meng, ZJ, Yan, SC, Yang, CP \& Ruan, CC. 2012 Asymmetrical distribution of antennal sensilla in the female Anastatus japonicus Ashmead (Hymenoptera: Eupelmidae).

Microscopy Research and Technique 75, 1066-1075.

Michener, CD. 1969 Comparative Social Behavior of Bees. Annual Review of Entomology 14, 299-342.

Michener, CD. 2007. The Bees of the World. 2nd edn., Johns Hopkins University Press, Baltimore, MD, United States.

Norton, WN \& Vinson, SB. 1974 Antennal sensilla of three parasitic Hymenoptera. International Journal of Insect Morphology and Embryology 3, 305-316. 
Nowińska, A \& Brożek, J. 2017 Morphological study of the antennal sensilla in Gerromorpha (Insecta: Hemiptera: Heteroptera). Zoomorphology 136, 327-347.

Rigosi, E, Frasnelli, E, Vinegoni, C, et al. 2011 Searching for anatomical correlates of olfactory lateralization in the honeybee antennal lobes: A morphological and behavioural study. Behav Brain Res, 290.

Rogers, LJ, Frasnelli, E \& Versace, E. 2016 Lateralized antennal control of aggression and sex differences in red mason bees, Osmia bicornis. Scientific Reports 6, 29411.

Rogers, LJ, Rigosi, E, Frasnelli, E \& Vallortigara, G. 2013 A right antenna for social behaviour in honeybees. Scientific Reports 3, 2045-2045.

Rogers, LJ \& Vallortigara, G. 2008 From Antenna to Antenna: Lateral Shift of Olfactory Memory Recall by Honeybees. PLOS ONE 3, 1-5.

Rogers, LJ, Zucca, P \& Vallortigara, G. 2004 Advantages of having a lateralized brain. Proceedings of the Royal Society of London. Series B: Biological Sciences 271, S420-S422. Schindelin, J, Arganda-Carreras, I, Frise, E, et al. 2012 Fiji: an open-source platform for biological-image analysis. Nat Methods 9, 676-682.

Schödl, S. 2004 On the taxonomy of Meranoplus puryi Forel, 1902 and Meranoplus puryi curvispina Forel, 1910 (Insecta: Hymenoptera: Formicidae). Annalen des Naturhistorischen Museums in Wien 105B, 349-360.

Spaethe, J, Brockmann, A, Halbig, C \& Tautz, J. 2007 Size determines antennal sensitivity and behavioral threshold to odors in bumblebee workers. Naturwissenschaften 94, 733-739. Stearns, SC. 1989 Trade-Offs in Life-History Evolution. Functional Ecology 3, 259-268. Thomas, ML, Parry, LJ, Allan, RA \& Elgar, MA. 1999 Geographic Affinity, Cuticular Hydrocarbons and Colony Recognition in the Australian Meat Ant Iridomyrmex purpureus. Naturwissenschaften 86, 87-92.

Tierney, SM, Friedrich, M, Humphreys, WF, Jones, TM, Warrant, EJ \& Wcislo, WT. 2017 Consequences of evolutionary transitions in changing photic environments. Austral Entomology 56, 23-46.

Wang, Y, Li, D, Liu, Y, Li, XJ, Cheng, WN \& Zhu-Salzman, K. 2016 Morphology, Ultrastructure and Possible Functions of Antennal Sensilla of Sitodiplosis mosellana Gehin (Diptera: Cecidomyiidae). Journal of Insect Science 16, 12. 
Warrant, EJ. 2017 The remarkable visual capacities of nocturnal insects: vision at the limits with small eyes and tiny brains. Philosophical Transactions of the Royal Society B:

Biological Sciences 372.

Wcislo, WT \& Engel, MS. 1996 Social Behavior and Nest Architecture of Nomiine Bees (Hymenoptera: Halictidae; Nomiinae). Journal of the Kansas Entomological Society 69, 158167.

Wcislo, WT \& Tierney, SM. 2009 Behavioural environments and niche construction: the evolution of dim-light foraging in bees. Biological Reviews 84, 19-37.

Wild, AL. 2007. Taxonomic revision of the ant genus Linepithema (Hymenoptera:

Formicidae), University of California Press, California, USA.

Zera, AJ \& Harshman, LG. 2001 The Physiology of Life History Trade-Offs in Animals. Annual Review of Ecology and Systematics 32, 95-126.

Zhukovskaya, M \& Lychakov, D. 2016 Asymmetry of Antennal Grooming in the Cockroach Periplaneta americana. Neuroscience \& Behavioral Physiology 46, 160-167.

Table 1. The effect of antenna side on antennal sensilla density (number of sensilla per $\mu \mathrm{m}^{2}$ ) of the apical antennomere in the Australian ants Iridomyrmex purpureus, Meranoplus sp. and Oecophylla smaragdina and the Australian bees Mellitidia tomentifera and Reepenia bituberculata. Data is presented as least squares mean $\pm \mathrm{SE}$. If ( $\mathrm{Ln}$ ) follows a measure, the natural $\log$ of that measure was analysed rather than raw measure to normalise the distribution. Statistically significant $p$-values are denoted by bolding and an * $\alpha=0.05$. 


\begin{tabular}{|c|c|c|c|c|c|}
\hline Sensilla type & Left antenna & Right antenna & df & F statistic & $p$ value \\
\hline \multicolumn{6}{|l|}{ Ants } \\
\hline \multicolumn{6}{|c|}{ Iridomyrmex purpureus } \\
\hline Trichoid-II & $6.69 \mathrm{E}-3 \pm 6.56 \mathrm{E}-4$ & $6.50 \mathrm{E}-3 \pm 6.56 \mathrm{E}-4$ & 1,7 & 0.0414 & 0.8445 \\
\hline Chaetica & $2.94 \mathrm{E}-3 \pm 2.39 \mathrm{E}-4$ & $3.08 \mathrm{E}-3 \pm 2.39 \mathrm{E}-4$ & 1,7 & 0.1752 & 0.6881 \\
\hline Basiconica & $7.34 \mathrm{E}-4 \pm 5.25 \mathrm{E}-5$ & $5.58 \mathrm{E}-4 \pm 5.25 \mathrm{E}-5$ & 1,7 & 5.621 & $0.0495^{*}$ \\
\hline $\begin{array}{l}\text { Trichodea curvata } \\
\text { (Ln) }\end{array}$ & $-6.278 \pm 0.135$ & $-6.411 \pm 0.135$ & 1,7 & 0.4772 & 0.5120 \\
\hline \multicolumn{6}{|l|}{ Meranoplus sp. } \\
\hline Trichoid-II & $3.96 \mathrm{E}-3 \pm 4.18 \mathrm{E}-4$ & $3.78 E-33.73 E-4$ & 1,6 & 0.1053 & 0.7566 \\
\hline Chaetica & $9.67 \mathrm{E}-4 \pm 2.17 \mathrm{E}-4$ & $1.06 \mathrm{E}-3 \pm 1.94 \mathrm{E}-4$ & 1,6 & 0.0958 & 0.7674 \\
\hline Basiconica & $5.48 \mathrm{E}-4 \pm 6.83 \mathrm{E}-5$ & $5.72 \mathrm{E}-4 \pm 6.11 \mathrm{E}-5$ & 1,6 & 0.0689 & 0.8018 \\
\hline $\begin{array}{l}\text { Trichodea curvata } \\
\text { (Ln) }\end{array}$ & $-7.061 \pm 0.168$ & $-7.056 \pm 0.150$ & 1,6 & 0.0005 & 0.9822 \\
\hline \multicolumn{6}{|c|}{ Oecophylla smaragdina } \\
\hline Trichoid-II (Ln) & $1.916 \pm 0.201$ & $1.737 \pm 0.220$ & 1,8 & 0.3582 & 0.5660 \\
\hline Chaetica (Ln) & $0.960 \pm 0.164$ & $0.998 \pm 0.180$ & 1,8 & 0.0243 & 0.8800 \\
\hline Basiconica (Ln) & $-0.281 \pm 0.197$ & $-0.295 \pm 0.216$ & 1,8 & 0.0023 & 0.9627 \\
\hline $\begin{array}{l}\text { Trichodea curvata } \\
\text { (Ln) }\end{array}$ & $0.369 \pm 0.135$ & $0.207 \pm 0.148$ & 1,8 & 0.6547 & 0.4418 \\
\hline \multicolumn{6}{|c|}{ Bees } \\
\hline \multicolumn{6}{|c|}{ Mellitidia tomentifera } \\
\hline Trichodea A & $6.55 \mathrm{E}-3 \pm 1.18 \mathrm{E}-3$ & $4.15 \mathrm{E}-3 \pm 1.18 \mathrm{E}-3$ & 1,9 & 2.066 & 0.1845 \\
\hline Trichodea B & $5.37 \mathrm{E}-4 \pm 1.27 \mathrm{E}-4$ & $4.21 \mathrm{E}-4 \pm 1.27 \mathrm{E}-4$ & 1,9 & 0.4150 & 0.5355 \\
\hline Basiconica (Ln) & $-7.770 \pm 0.280$ & $-7.583 \pm 0.280$ & 1,9 & 0.2233 & 0.6478 \\
\hline Chaetica (Ln) & $-7.953 \pm 0.261$ & $-7.967 \pm 0.261$ & 1,9 & 0.0014 & 0.9713 \\
\hline Placodea (Ln) & $-5.448 \pm 0.109$ & $-5.534 \pm 0.109$ & 1,9 & 0.3148 & 0.5884 \\
\hline \multicolumn{6}{|c|}{ Reepenia bituberculata } \\
\hline Trichodea A & $8.94 \mathrm{E}-3 \pm 2.12 \mathrm{E}-3$ & $5.14 \mathrm{E}-3 \pm 2.12 \mathrm{E}-3$ & 1,7 & 1.6005 & 0.2463 \\
\hline Trichodea B & $1.06 \mathrm{E}-3 \pm 1.57 \mathrm{E}-4$ & $8.56 \mathrm{E}-4 \pm 1.57 \mathrm{E}-4$ & 1,7 & 0.8073 & 0.3988 \\
\hline Basiconica (Ln) & $-7.021 \pm 0.194$ & $-7.326 \pm 0.194$ & 1,7 & 1.2294 & 0.3042 \\
\hline Chaetica (Ln) & $-7.997 \pm 0.131$ & $-8.064 \pm 0.131$ & 1,7 & 0.1305 & 0.7286 \\
\hline Placodea (Ln) & $-5.543 \pm 0.195$ & $-5.941 \pm 0.195$ & 1,7 & 2.0910 & 0.1914 \\
\hline
\end{tabular}

This article is protected by copyright. All rights reserved. 


\section{Figure Legends}

Figure 1. Scanning electron micrographs of the antennal sensilla of (A) the Australian green tree ant Oecophylla smaragdina and (B) an Australian native bee Reepenia bituberculata. Sensilla trichodea, trichodea curvata, basiconica and placodea are chemosensory/olfactory sensilla and sensilla chaetica are mechanosensory sensilla. Scale bars are $10 \mu \mathrm{m}$.

This article is protected by copyright. All rights reserved. 


\section{Figure 1}
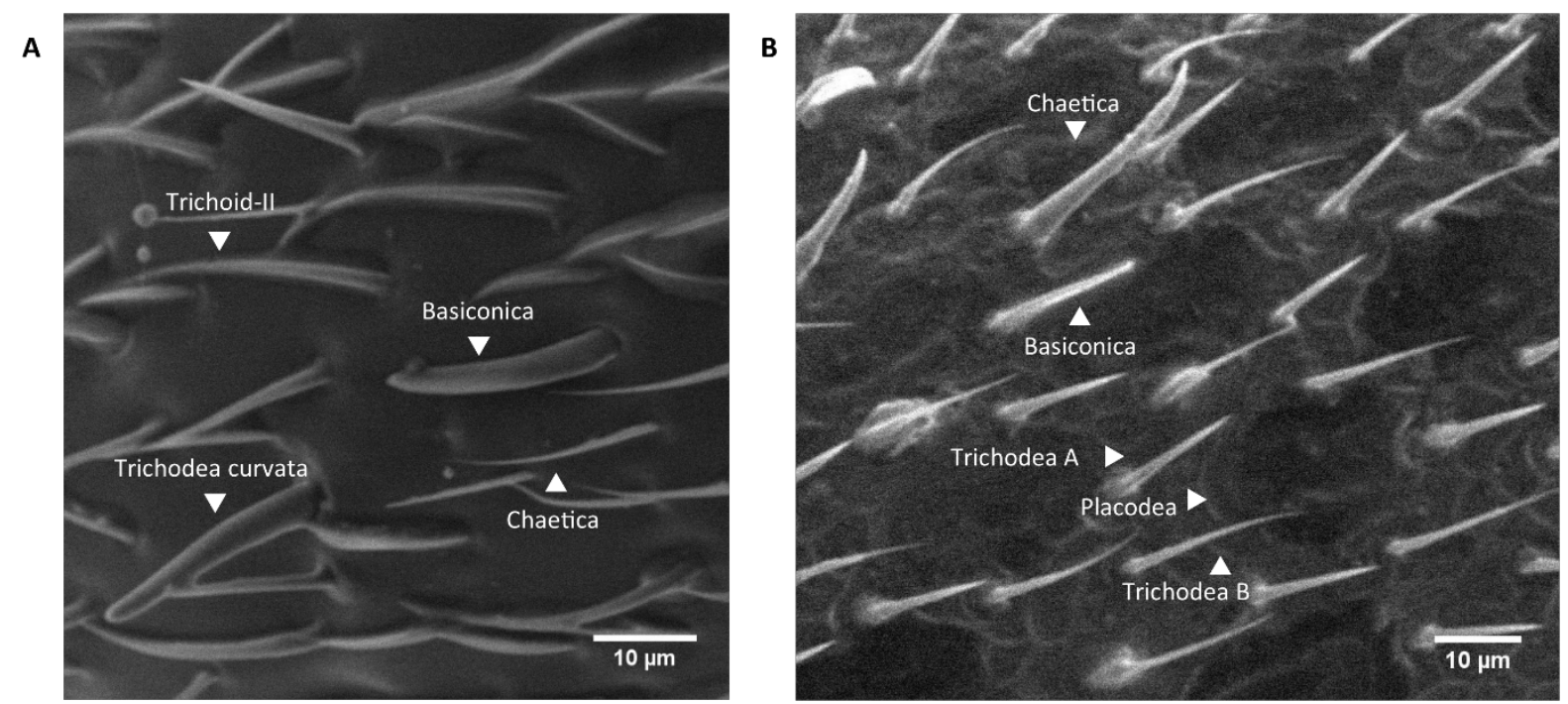

This article is protected by copyright. All rights reserved. 
A

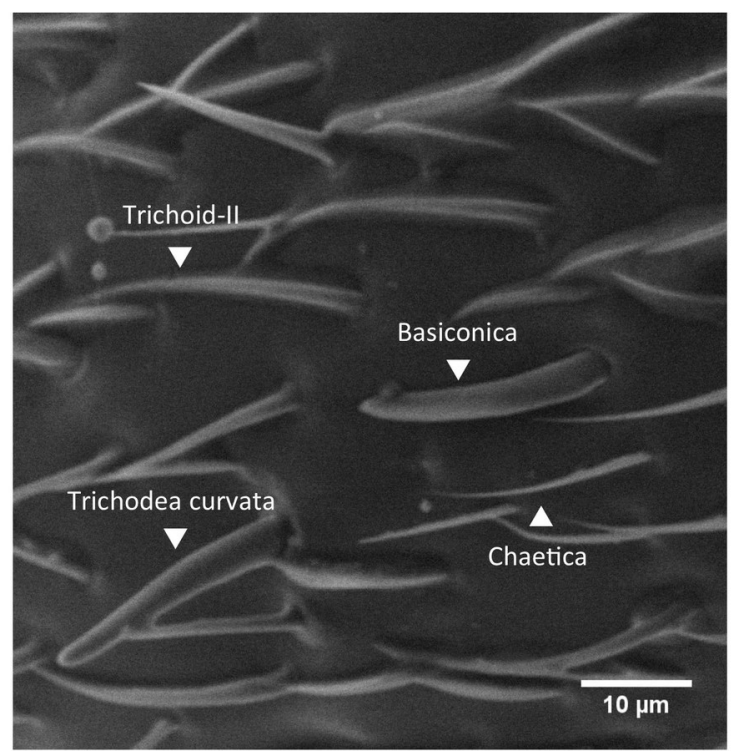

B

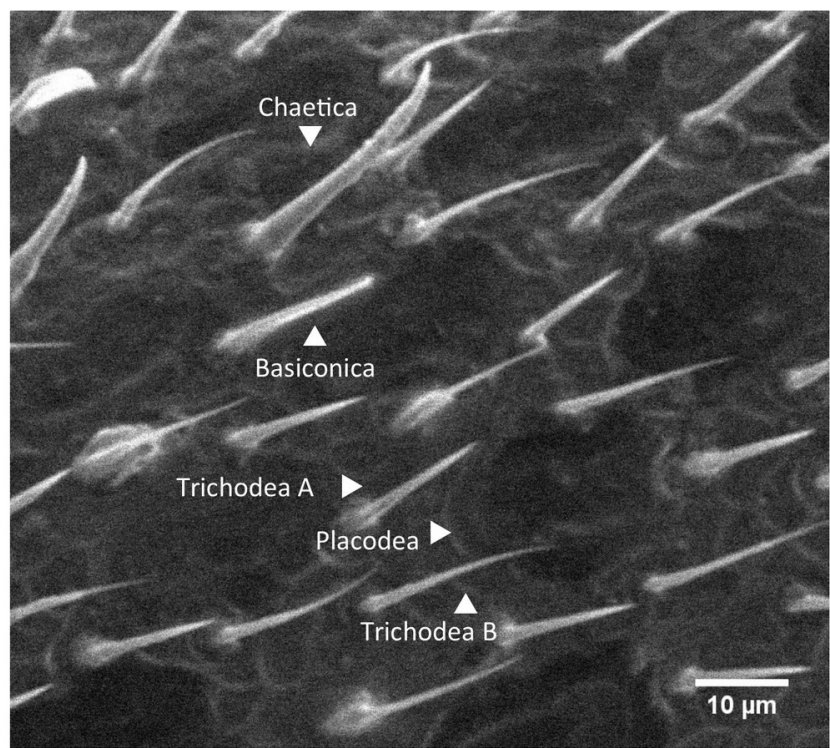

AEN_12368_F1.jpg

This article is protected by copyright. All rights reserved. 


\section{University Library}

\section{- M M N E R VA A gateway to Melbourne's research publications}

Minerva Access is the Institutional Repository of The University of Melbourne

Author/s:

Freelance, CB;Majoe, M;Tierney, SM;Elgar, MA

Title:

Antennal asymmetry is not associated with social behaviour in Australian Hymenoptera

Date:

2019-08-01

Citation:

Freelance, C. B., Majoe, M., Tierney, S. M. \& Elgar, M. A. (2019). Antennal asymmetry is not associated with social behaviour in Australian Hymenoptera. AUSTRAL ENTOMOLOGY, 58 (3), pp.589-594. https://doi.org/10.1111/aen.12368.

Persistent Link:

http://hdl.handle.net/11343/284429 